\title{
Comparative Evaluation of GFAAS and ICP-MS for Analyses of Cadmium in Blood
}

\author{
Yoshinari FUKUI ${ }^{1}$, Fumiko OHASHI ${ }^{1}$, Sonoko SAKURAGI ${ }^{2}$, \\ Jiro MORIGUCHI ${ }^{2}$ and Masayuki IKEDA ${ }^{1 *}$
}

\author{
${ }^{1}$ Kyoto Industrial Health Association (Main Office), 67 Nishinokyo-Kitatsuboicho, Nakagyo-ku, Kyoto \\ 804-8472, Japan \\ ${ }^{2}$ Kyoto Industrial Health Association (Mibu Office), 4-1 Mibu-Shujakucho, Nakagyo-ku, Kyoto 804-8871, \\ Japan
}

Received January 21, 2010 and accepted September 30, 2010

Published online in J-STAGE March 1, 2011

\begin{abstract}
Cadmium in blood (Cd-B) is an important indicator, next to $\mathrm{Cd}$ in urine, in biological monitoring of exposure to $\mathrm{Cd}$. The present study was initiated to examine compatibility in results of analysis for Cd-B between graphite furnace atomic absorption spectrophotometry (GFAAS) and inductively-coupled plasma mass-spectrometry (ICP-MS). For this purpose, 1,159 blood samples were collected from adult women (with no occupational exposure to $\mathrm{Cd}$ ) in eight prefectures nation-widely in Japan. The samples were analyzed by the two methods; geometric mean (the maximum) concentrations were $1.22(6.90) \mu \mathrm{g} / \mathrm{l}$ by ICP-MS, and $1.47(7.40) \mu \mathrm{g} / \mathrm{l}$ by GFAAS. Statistical analyses showed that there was a close correlation between the results by the two methods. The regression line (with ICP-MS and GFAAS results as an independent variable and a dependent variable, respectively) had a slope close to one and an intercept next to zero to suggest that ICP-MS gave values compatible with that of GFAAS. Further analysis with the ratio of Cd-B by GFAAS over that by ICP-MS revealed that the two results were close to each other, and that the agreement was even closer when Cd-B was $>2 \mu \mathrm{g} / \mathrm{l}$. Thus, the two methods can be employed inter-convertibly when Cd-B is relatively high, e.g. $>2 \mu \mathrm{g} / \mathrm{l}$. Care may need to be practiced, however, for possible 'between methods' difference when Cd-B is low, e.g., $\leq 2 \mu \mathrm{g} / \mathrm{l}$.
\end{abstract}

Key words: Blood, Cadmium, GFAAS, ICP-MS, Population with no occupational exposure

\section{Introduction}

Cadmium $(\mathrm{Cd})$ is a typical toxic pollutant metal ubiquitous in the general environment ${ }^{1)}$, and monitoring for $\mathrm{Cd}$ concentration in biological materials is one of the most common procedures to assess $\mathrm{Cd}$ exposure of working populations with occupational exposure to this metal as well as general populations with $\mathrm{Cd}$ exposures via general environment ${ }^{2-4}$.

With regard to the methods of analysis for biological exposure monitoring, graphite furnace atomic absorption spectrophotometry (GFAAS) has been enjoying high reputation as a reliable method for determination of $\mathrm{Cd}$ in

*To whom correspondence should be addressed.

E-mail: ikeda@hokenkai.jp biological materials such as blood and urine ${ }^{4}$. In recent years, increasing attention has been paid to inductivelycoupled plasma-mass spectrometry (ICP-MS) as a method for metal analysis with the instrument and material limits of determination substantially lower than that for GFAAS $^{5,6)}$. Nevertheless, studies on the compatibility between the two methods are few in literature; only two reports $\left.{ }^{7}, 8\right)$ are available with conflicting results.

It was the purpose of the present study to examine, with more than 1,000 samples, if cadmium in blood (Cd-B) measured by ICP-MS agrees with that by GFAAS. Efforts were further extended to find critical Cd-B levels below which discrepancy would be large enough to be a matter of concern. 


\section{Subjects, Materials, Methods and Ethical Issues}

\section{Subjects and materials}

Peripheral blood samples were collected from adult women (mostly non-smoking) in 2002 to 2008 in eight prefectures nation-widely in Japan.

\section{Ethical issues}

The study protocol was approved by the Ethics Committee, Kyoto Industrial Health Association, Kyoto, Japan, and each of the participating women provided her informed consent in writing.

\section{Blood analyses for $C d$}

Analyses for Cd-B were conducted by two methods. For GFAAS analysis, $200 \mu 1$ of blood was mixed with $100 \mu 1$ of $10 \%$ Triton in water, $200 \mu 1$ of $10 \%$ diammonium hydrogen phosphate in water and $200 \mu \mathrm{l}$ of $0.1 \mathrm{~N}$ nitric acid. A $10 \mu \mathrm{l}$ portion of the mixture was introduced to a GFAAS (Hitachi polarized Zeeman atomic absorption spectrophotometer, Z-5710, Hitachi High-technologies Corp., Tokyo, Japan) by use of an auto-sampler. The measurement was made at $288.8 \mathrm{~nm}$ under the operation conditions previously described in detail ${ }^{9}$. In case of ICP-MS analysis, an aliquot $(100 \mu \mathrm{l})$ of each blood sample was digested in presence of $500 \mu \mathrm{l}$ of $68 \%$ (about $14.8 \mathrm{~N}$ ) nitric acid in a closed vessel by the microwave method, and the digest was taken up in $5 \mathrm{ml}$ of ultra-pure water. The solution was introduced to an ICP-MS system (Thermo Scientific ELEMENT2 High Performance High Resolution ICPMS, Thermo Fisher Scientific Inc, Bremen, Germany) as previously detailed ${ }^{6}$. The standard addition method was employed for quantification in both analytical methods.

Data on Cd-B measured by ICP-MS were cited from Ikeda and others ${ }^{6}$, whereas Cd-B analyses by GFAAS were conducted anew for the present study. In practice, complete data sets (i.e., Cd-B both by ICP-MS and by GFAAS) were available for 1,159 cases. The method limit of determination (LOD) for Cd-B analysis by ICPMS was $0.1 \mu \mathrm{g} / 1^{6}$ ), and that by GFAAS was $0.5 \mu \mathrm{g} / \mathrm{l}$ as previously described ${ }^{8)}$. The quality of analysis for Cd both by ICP-MS and by GFAAS was approved by G-EQUAS (External Inter-comparison Programme 2002 and 2009).

\section{Quality control standard material}

The quality control standard material for trace elements in human whole blood consisted of two preparations of Level 1 (SERO201505; $\mathrm{Cd}-\mathrm{B} \doteqdot 0.7 \mu \mathrm{g} / \mathrm{l})$ and Level 2 (SERO201605; Cd-B $\doteqdot 6 \mu \mathrm{g} / \mathrm{l}$ ), and was supplied by SERO AS, Billingstad, Norway.

\section{Statistical analyses}

A normal distribution was considered for age and a log-normal distribution for $\mathrm{Cd}-\mathrm{B}^{1-3)}$, so that the distributions of the former and the latter were expressed in terms of arithmetic means (AMs) \pm arithmetic standard deviations (ASDs) and geometric means (GMs) [geometric standard deviations (GSDs)], respectively. In some instances, medians (MEDs), and the minimum (Min.) and the maximum values (Max.) were also shown. In case the analyte concentration was below LOD (in practice, such was observed only in 17 cases of Cd-B by GFAAS), a half the LOD was taken in the place. Parametric $t$-test was applied to detect possible difference between the pairs, before or after logarithmic conversion as necessary. Regression analysis and correlation matrix analysis were also employed.

\section{Results}

Analyses of quality control standard materials by ICP$M S$ and GFAAS

The pair of the standard materials (Level 1 and Level 2) was analyzed by ICP-MS and by GFAAS (Table 1). The standard values for quality control attached to the materials were given in terms of $\mathrm{AM}$ and the $95 \%$ confidence intervals (the 95\% CI), one set each for ICPMS and for GFAAS. The AM and ASD for the values measured in the present study were based on 10 deter-

Table 1. Comparison of experimental values with quality control standard values

\begin{tabular}{|c|c|c|c|c|}
\hline \multirow{2}{*}{$\begin{array}{l}\text { Reference material } \\
\text { Parameter }\end{array}$} & \multicolumn{2}{|c|}{ ICP-MS } & \multicolumn{2}{|c|}{ GFAAS } \\
\hline & Standard & $\begin{array}{l}\text { Experi- } \\
\text { mental }\end{array}$ & Standard & $\begin{array}{l}\text { Experi- } \\
\text { mental }\end{array}$ \\
\hline \multicolumn{5}{|l|}{ Level 1} \\
\hline $\mathrm{AM}$ & 0.74 & 0.69 & 0.7 & 0.78 \\
\hline ASD & & 0.03 & & 0.03 \\
\hline $95 \%$ CI & 0.68 to 0.80 & & 0.4 to 1.0 & \\
\hline $\mathrm{CV}(\%)$ & 49.1 & 4.6 & 26.0 & 3.6 \\
\hline \multirow{2}{*}{ Recovery (\%) } & & 93 & & 111 \\
\hline & & & & $105^{\mathrm{a}}$ \\
\hline \multicolumn{5}{|l|}{ Level 2} \\
\hline $\mathrm{AM}$ & 6.0 & 6.04 & 5.1 & 6.92 \\
\hline ASD & & 0.57 & & 0.22 \\
\hline $95 \%$ CI & 5.6 to 6.4 & & 2.8 to 7.4 & \\
\hline $\mathrm{CV}(\%)$ & 4.0 & 9.5 & 27.3 & 3.2 \\
\hline \multirow[t]{2}{*}{ Recovery (\%) } & & 101 & & 136 \\
\hline & & & & $115^{\mathrm{a}}$ \\
\hline
\end{tabular}

Unless otherwise specified, the values in the table are in $\mu \mathrm{g} / \mathrm{l}$.

$\mathrm{AM}, \mathrm{ASD}, \mathrm{CI}$ and $\mathrm{CV}$ stand for arithmetic mean, arithmetic standard deviation, confidence interval and coefficient of variation (i.e., ASD/AM in \%), respectively.

Recovery is defined as experimental value/certified value in $\%$. $\mathrm{n}=10$ for experimental values by GFAAS and ICP-MS.

${ }^{\text {a}}$ Recovery in reference to the standard values for ICP-MS 
minations each.

The AM experimental values for ICP-MS and GFAAS were all in the corresponding 95\% confidence intervals. $\mathrm{CV}$ values (i.e., ASD/AM in \%) were 4.6 (Level 1) and 9.5\% (Level 2) for ICP-MS, and 3.6 (Level 1) and 3.2\% (Level 2) for GFAAS, the former CVs being larger than the latter values. The recovery rate (i.e., the rate of experimental value over the standard value for quality control in AM) was 93 (Level 1) and 101\% (Level 2) for ICP-MS, and 111 (Level 1) and 136\% (Level 2) for GFAAS.

\section{Basic parameters}

The distributions of age and $\mathrm{Cd}-\mathrm{B}$ as measured by ICP-MS and GFAAS are summarized in Table 2. The mean age of the participants was $43.7 \mathrm{yr}$ scattering in a wide range of 20 to $74 \mathrm{yr}$. Age correlated weakly but significantly with $\mathrm{Cd}-\mathrm{B}$ ( $\mathrm{r}=0.184$ for $\mathrm{Cd}-\mathrm{B}$ by ICP-MS, and 0.215 for Cd-B by GFAAS; $p<0.01$ for both coefficients).

GM for Cd-B as measured by ICP-MS, $1.22 \mu \mathrm{g} / 1$, was slightly smaller (by 17\%) than that by GFAAS $(1.47 \mu \mathrm{g} / \mathrm{l})$. Comparison of the two values before and after logarithmic conversion by paired $t$-test showed that the difference was significant $(p<0.01)$ irrespective of logarithmic conversion.

Table 2. Basic parameters

\begin{tabular}{lcccc}
\hline Parameter $^{\mathrm{a}}$ & $\begin{array}{c}\text { Age } \\
(\mathrm{yr})\end{array}$ & $\begin{array}{c}\text { ICP-MS } \\
(\mu \mathrm{g} / \mathrm{l})\end{array}$ & $\begin{array}{c}\text { GFAAS } \\
(\mu \mathrm{g} / \mathrm{l})\end{array}$ & Ratio $^{\mathrm{b}}$ \\
\hline GM & $43.7^{\mathrm{c}}$ & 1.22 & 1.47 & 1.2 \\
GSD & $10.2^{\mathrm{c}}$ & 1.70 & 1.66 & 1.0 \\
MED & 44 & 1.2 & 1.5 & 1.3 \\
Min. & 20 & 0.1 & $<$ LOD $^{\mathrm{d}}$ & $\mathrm{NC}$ \\
Max. & 74 & 6.9 & 7.4 & 1.1 \\
\hline
\end{tabular}

In total, 1,159 cases were studied.

${ }^{\mathrm{a}} \mathrm{AM}, \mathrm{ASD}, \mathrm{GM}, \mathrm{GSD}, \mathrm{MED}$, Min. and Max. stand for arithmetic mean, arithmetic standard deviation, geometric mean, geometric standard deviation, median, the minimum and the maximum, respectively. ${ }^{\mathrm{b}}$ The ratio of Cd-B by GFAAS ( $\left.\mu \mathrm{g} / \mathrm{l}\right)$ over Cd-B by ICP-MS $(\mu \mathrm{g} / \mathrm{l})$.

${ }^{\mathrm{c}} \mathrm{AM}$ and $\mathrm{ASD}$ in place of GM and GSD.

${ }^{\mathrm{d}} \mathrm{LOD} ; 0.1 \mu \mathrm{g} / \mathrm{l}$ for ICP-MS and $0.5 \mu \mathrm{g} / \mathrm{l}$ for GFAAS.

eNot calculable.
Difference in Cd-B between ICP-MS and GFAAS as a function of $C d-B$

Regression analyses taking Cd-B by ICP-MS as an independent variable and that by GFAAS as a dependent variable (the first line in Table 3 ) showed that there was a close correlation $(\mathrm{r}=0.964, p<0.01)$ between the pairs, and the slope was close to one (i.e., 1.059) whereas the intercept was next to zero. Similar analysis with the values after logarithmic conversion (the second line in Table 3) gave essentially the same results with one difference that the slope was slightly smaller than one (i.e., 0.895). Plotting of the paired values on the ordinary scales taking Cd-B by ICP-MS on the horizontal $(\mathrm{X})$ axis and that by GFASS on the vertical $(\mathrm{Y})$ axis showed that there was a close correlation between the pairs with a regression line close to $\mathrm{Y}=\mathrm{X}$ but the range of scattering around the regression line appeared to be wider as a reverse function of Cd-B (Fig. 1). The trend of wider scattering at lower Cd-B was clearer when the

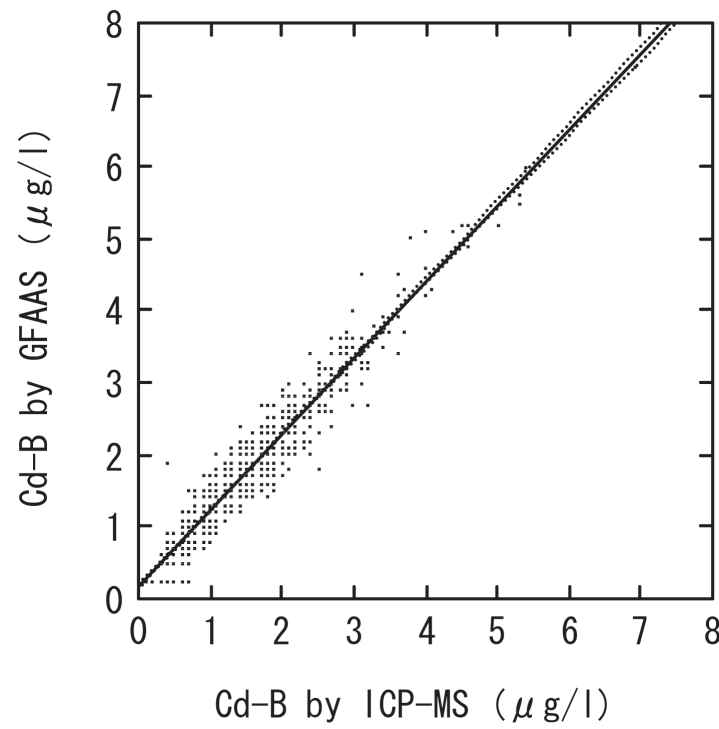

Fig. 1. Correlation of Cd-B values as measured by ICP-MS and by GFAAS.

Each dot represents one case $(\mathrm{n}=1,159)$.

The line in the middle is a calculated regression line $(\mathrm{Y}=0.174+1.059 \mathrm{X})$, and two dotted curves on both sides show the $95 \%$ confidence interval.

Table 3. Parameters of regression analysis

\begin{tabular}{|c|c|c|c|c|c|c|c|c|}
\hline Independent variable & Dependent variable & Intercept & $(95 \% \mathrm{CI})$ & Slope & $(95 \% \mathrm{CI})$ & $\mathrm{r}$ & $p$ for $\mathrm{r}$ & Note \\
\hline Cd-B by ICP-MS $(\mu \mathrm{g} / 1)^{\mathrm{a}}$ & Cd-B by GFAAS $(\mu \mathrm{g} / \mathrm{l})$ & 0.174 & (0.147 to 0.201$)$ & 1.059 & ( 1.042 to 1.076$)$ & 0.964 & $<0.01$ & Fig. 1 \\
\hline $\log [\mathrm{Cd}-\mathrm{B} \text { by ICP-MS }(\mu \mathrm{g} / \mathrm{l})]^{\mathrm{a}}$ & $\log [\mathrm{Cd}-\mathrm{B}$ by GFAAS $(\mu \mathrm{g} / \mathrm{l})]$ & 0.089 & (0.084 to 0.093$)$ & 0.895 & ( 0.876 to 0.9141 ) & 0.938 & $<0.01$ & Fig. 2 \\
\hline Cd-B by ICP-MS $(\mu \mathrm{g} / \mathrm{l})^{\mathrm{a}}$ & The ratio ${ }^{c}$ & 1.348 & (1.321 to 1.376$)$ & -0.090 & $(-0.107$ to -0.073$)$ & 0.291 & $<0.01$ & Fig. 3 \\
\hline Cd-B by ICP-MS $(\mu \mathrm{g} / 1)^{\mathrm{b}}$ & The ratio ${ }^{c}$ & 1.155 & (1.015 to 1.295$)$ & -0.012 & $(-0.049$ to 0.025$)$ & 0.092 & $>0.10$ & \\
\hline
\end{tabular}

$a_{n}=1,159$.

${ }^{\mathrm{b}} \mathrm{Cd}-\mathrm{B}>3 \mu / \mathrm{g}$ (by ICP-MS) was selected ( $\mathrm{n}=52$ ).

'The ratio of [Cd-B by GFAAS $(\mu \mathrm{g} / \mathrm{l})$ ] over [Cd-B by [ICP-MS $(\mu \mathrm{g} / \mathrm{l})]$. 
values were logarithmically converted (Fig. 2). For further analysis, the ratio of Cd-B by GFAAS over Cd-B by ICP-MS was calculated for each case and plotted against Cd-B by ICP-MS. The plotting (Fig. 3) showed that the ratio scattered in a wider range when $\mathrm{Cd}-\mathrm{B}$ was smaller (e.g., $<1 \mu \mathrm{g} / \mathrm{l}$ ) but tended to converge toward a horizontal line as a function of increasing Cd-B (e.g. $\geq 2 \mu \mathrm{g} / \mathrm{l})$.

Figure 3 might be misleading because more cases were available in lower Cd-B ranges and the variation in the ratio could be greater simply due to a larger number of the cases. Thus, slopes of the regression lines and coefficients of variation were compared for Cd-B of different concentration ranges. Cases were classified in terms of a Cd-B range of $1.0 \mu \mathrm{g} / \mathrm{l}$ (starting from $<\mathrm{LOD}$ )

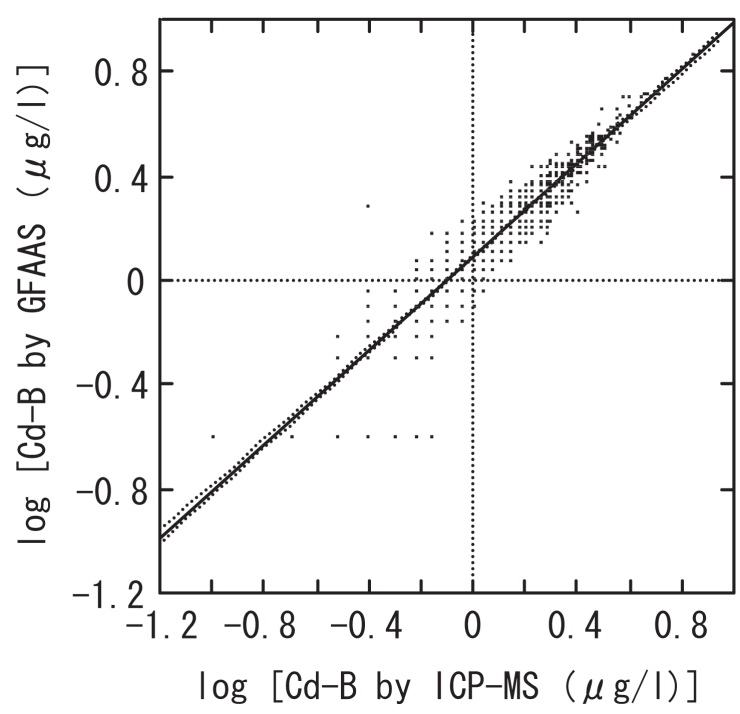

Fig. 2. Correlation of log Cd-B values as measured by ICPMS and that by GFAAS.

The meaning of the line $(\mathrm{Y}=0.089+0.895 \mathrm{X})$, two curves and dots are as in Fig. 1. and with an increase of $0.5 \mu \mathrm{g} / \mathrm{l}$ (i.e., $<\mathrm{LOD}$ to $<1.0 \mu \mathrm{g} / \mathrm{l}$, 0.5 to $<1.5 \mu \mathrm{g} / \mathrm{l}, 1.0$ to $<2.0 \mu \mathrm{g} / \mathrm{l}$ and so on; Table 4). The slope for all cases in combination was negative $(<0)$, i.e., -0.090 , with the $95 \% \mathrm{CI}$ of -0.107 to -0.073 ) but it was essentially zero when cases with $\mathrm{Cd}-\mathrm{B} \geq 3 \mu \mathrm{g} / \mathrm{l}$ $(\mathrm{n}=52)$ were selected (the bottom line in Table 3). In fact, the slope was already zero in the Cd-B range of 2 to $<3 \mu \mathrm{g} / 1$ (the $95 \%$ range for the slope of -0.075 to 0.057 , $\mathrm{n}=156$; in the middle of Table 4). In contrast, the slope for $\mathrm{Cd}-\mathrm{B}$ range of $<2 \mu \mathrm{g} / \mathrm{l}$ was negative, i.e., -0.455 to -0.131 , and the upper limit of $95 \%$ range was also less than zero (Table 4). Coefficients of variation converged to $10 \%$ in the higher $\mathrm{Cd}-\mathrm{B}$ ranges.

After convergence to a horizontal line, the intercept for the fourth equation in Table 4 (with 52 cases in the Cd-B range of $\geq 3 \mu \mathrm{g} / \mathrm{l}$ ) was 1.155 (the $95 \% \mathrm{CI} ; 1.015$ to 1.295). The observation suggests that GFAAS would

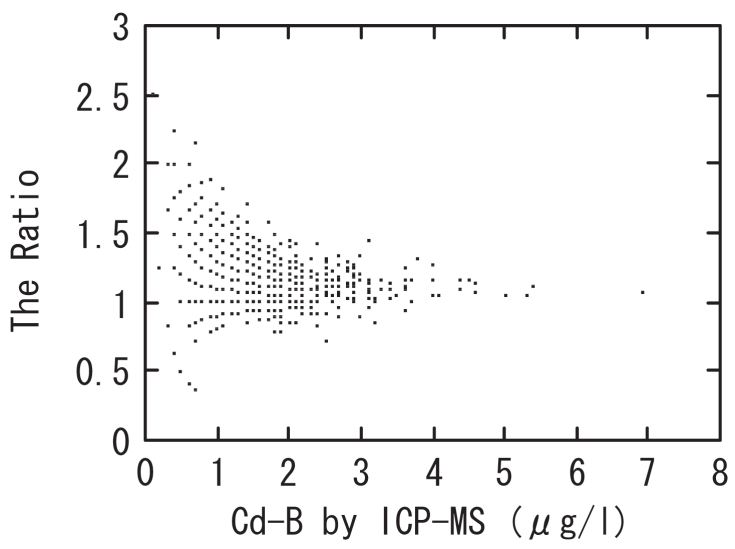

Fig. 3. Relationship of Cd-B (by ICP-MS) with the ratio of Cd-B by GFAAS over that by ICP-MS.

Note a wide dispersion when Cd-B is low (e.g., $<2 \mu \mathrm{g} / \mathrm{l}$ ) and a conversion to a zone of the ratio $=1.0$ to 1.2 when $\mathrm{Cd}-\mathrm{B}$ is high (e.g., $>4 \mu \mathrm{g} / \mathrm{l})$.

Table 4. Changes in slope as a function of Cd-B

\begin{tabular}{|c|c|c|c|c|c|c|c|c|c|}
\hline \multicolumn{3}{|c|}{$\mathrm{Cd}-\mathrm{B}^{\mathrm{a}}$} & \multicolumn{3}{|c|}{ The ratio ${ }^{\mathrm{b}}$} & \multicolumn{4}{|c|}{ Regression line } \\
\hline Range & $\mathrm{n}$ & MED & $\mathrm{AM}$ & ASD & $\mathrm{CV}$ & Slope & $(95 \% \mathrm{CI})$ & $|r|$ & $p$ \\
\hline$<\operatorname{LOD}^{\mathrm{c}}$ to 1.0 & 357 & 0.7 & 1.32 & 0.35 & 26.1 & -0.455 & ( -0.657 to -0.252$)$ & 0.228 & $<0.01$ \\
\hline 0.5 to 1.5 & 692 & 1.0 & 1.25 & 0.22 & 17.2 & -0.211 & $(-0.270$ to -0.152$)$ & 0.257 & $<0.01$ \\
\hline 1.0 to 2.0 & 594 & 1.3 & 1.19 & 0.16 & 13.6 & -0.131 & $(-0.178$ to -0.084$)$ & 0.219 & $<0.01$ \\
\hline 1.5 to 2.5 & 317 & 1.8 & 1.15 & 0.14 & 12.1 & -0.085 & $(-0.139$ to -0.030$)$ & 0.170 & $<0.01$ \\
\hline 2.0 to 3.0 & 156 & 2.4 & 1.13 & 0.12 & 10.7 & -0.009 & $(-0.075$ to 0.006$)$ & 0.022 & $>0.10$ \\
\hline 2.5 to 3.5 & 87 & 2.9 & 1.13 & 0.11 & 10.1 & -0.035 & $(-0.132$ to 0.062$)$ & 0.078 & $>0.10$ \\
\hline 3.0 to 4.0 & 38 & 3.2 & 1.11 & 0.12 & 10.5 & 0.003 & $(-0.153$ to 0.16$)$ & 0.006 & $>0.10$ \\
\hline 3.0 and over & 52 & 3.4 & 1.11 & 0.10 & 9.4 & -0.012 & $(-0.049$ to 0.03$)$ & 0.092 & $>0.10$ \\
\hline
\end{tabular}

Abbreviations are as under Tables 1 and 2.

${ }^{\text {aB }}$ ICP-MS (unit: $\mu \mathrm{g} / \mathrm{l}$ ).

${ }^{b}$ The ratio of Cd by GFAAS over Cd by ICP-MS.

${ }^{c} \mathrm{LOD}=0.1 \mu \mathrm{g} / 1$. 
give about $16 \%$ greater value than ICP-MS, and that the difference in the results by the two analytical methods should be stabilized at higher Cd-B, e.g., Cd-B of $2 \mu \mathrm{g} / 1$ or greater (Table 4).

\section{Discussion}

Analytical principles for ICP-MS and GFAAS are quite different, measurement of mass of the selected isotope in the former method and that of light intensity after heat atomization of the element in the latter. In the present analyses, the standard addition method was employed in both analyses. It should be noted that the between-methods agreement may be influenced not only by the characteristics of the instrument employed and analytical conditions including the performance of the instruments, but also by the materials analyzed. Accordingly, allowance for the difference in analysis results between methods should be more generous than the case of traditional analysis for chemicals especially when a organics-rich complex matrix such as blood is subjected to the analysis. In practice, changes by $< \pm 20 \%$ was considered to be slight in the present study.

Analyses of the standard materials (Table 1) with Cd-B at two different levels, i.e., Level 1 at ca. $0.7 \mu \mathrm{g} / 1$ and Level 2 at ca. $6 \mu \mathrm{g} / \mathrm{l}$, showed that GFAAS-based values were slightly greater (13 and $15 \%$ at Levels 1 and 2, respectively) than corresponding ICP-MS-based values. In this respect, the difference in the quality control standard values being lower for GFAAS than that for ICP-MS was quite contrary to the expectation. The recovery (an indicator of accuracy) was better for ICPMS (93 and 101\%) than for GFAAS (111 and 136\%), whereas the $\mathrm{CV}$ (a precision indicator) was better for GFAAS (3.2 and 3.6\%) than for ICP-MS (4.6 and 9.5\%). It should be added that both experimental AM values (by ICP-MS and by GFAAS) were well within the $95 \%$ confidence intervals of the quality control standard values (Table 1). The LOD is lower for ICP-MS than for GFAAS but both are sufficiently low for Cd-B determination in practice. Thus, it was difficult to identify the superiority between the two methods, even though the equipment for ICP-MS is several times more expensive than that for GFAAS.

In the present survey, blood samples were collected from a large number of subjects (1,159 adult women) who had no occupational exposure to $\mathrm{Cd}$. The participating subjects were solely from Japan, which may allow expectation that potential effects of ethnic life factors, if they are, should be minimal in applying the present study conclusion to $\mathrm{Cd}-\mathrm{B}$ analysis among Japanese populations. The large number of cases made it possible to carry out detailed analysis of Cd-B leveldependent changes in compatibility of the results by two analysis methods (e.g., Fig. 3 and Table 4).

The present analyses taking Cd-B by ICP-MS as an independent variable and Cd-B by GFAAS as a dependent variable clearly demonstrated that $\mathrm{Cd}-\mathrm{B}$ values as measured by the two methods correlate closely with each other $(\mathrm{r}=0.964, p<0.01)$. The slope, 1.059 , was greater than 1.0 by $5.5 \%$ suggesting that the values by GFAAS would be slightly greater than the values by ICP-MS. Further analysis showed that the variations in the agreement in the results between the two methods were wider when Cd-B was smaller (e.g., $\leq 2 \mu \mathrm{g} / 1$; Table 4) whereas the ratio of Cd-B by GFAAS over that by ICP-MS converged to a constant of 1.155 when Cd-B was e.g., $>3 \mu \mathrm{g} / \mathrm{l}$ (Table 4).

As discussed above, literature survey showed that only two reports $\left.{ }^{7}, 8\right)$ are available on possible difference in results on Cd-B between ICP-MS and GFAAS. Zhang et al. ${ }^{7}$ analyzed 418 blood samples collected from residents (with no occupational exposure to $\mathrm{Cd}$ ) in Japan and China (Cd-B being up to $3 \mu \mathrm{g} / \mathrm{l}$ as $\mathrm{GMxGSD}^{1.65}$ ). GM Cd-B by ICP-MS was $83 \%$ of that by GFAAS. When $\log$ [Cd-B by GFAAS] and log [Cd-B by ICP-MS] were taken as an independent and a dependent variable, respectively, the slope of the regression line was 0.92 ( 0.78 for 198 Chinese cases and 0.96 for 220 Japanese cases), suggesting that ICP-MS gave lower values than GFAAS. Furthermore, the agreement was better for the one-third group of the highest Cd-B $(88 \%)$ than the middle $(82 \%)$ or the lowest onethird $(81 \%)$. The findings as a whole are very similar to the present observation in the sense that the correlation is close between the two sets of measurements, that ICP-MS gives slightly lower values than GFAAS, and that the agreements are better for the cases with higher Cd-B than the cases with lower Cd-B. White ${ }^{8)}$ compared results of measurement of 90 samples for $\mathrm{Cd}-\mathrm{B}$ (0.06 to $7 \mu \mathrm{g} / \mathrm{l})$ by the two methods and found very close correlation between the paired values; the correlation coefficient was as high as $>0.99$ and the slope was 1.03. Although the slope may suggest that ICPMS gave slightly larger values than GFAAS, no detailed statistical evaluation was reported, unfortunately.

Separate from blood or Cd, Ndung'u et al. ${ }^{10)}$ analyzed $\mathrm{Pb}$ in four wine vinegar samples by the two methods and found that ICP-MS gave smaller values than GFAAS (88 to 98\%). Townsend et al. ${ }^{11)}$ in contrast found no difference between the results of analysis by the two methods when they measured $\mathrm{Cd}$ in eight water samples from a river. From literature survey, therefore, it may be possible to conclude that ICP-MS gives no higher values than GFAAS. 
The observation on between-methods difference may carry practical implication that both methods can be used inter-convertibly in the $\mathrm{Cd}-\mathrm{B}$ range around the biological exposure index (BEI) of $5 \mu \mathrm{g} / \mathrm{l}^{3)}$ or higher, but care should be practiced for the method-dependent difference when dealing with samples from general populations with low GM Cd-B levels, e.g., 0.28 to $0.71 \mu \mathrm{g} / 1^{12-15)}$ (the values are after conversion from $\mathrm{AM}$ to $\mathrm{GM}$ by the moment method ${ }^{16)}$ for uniformity in presentation). Nuttal et $a l^{12)}$, for example, obtained $0.71 \mu \mathrm{g} / \mathrm{l} \mathrm{Cd}-\mathrm{B}$ as GM by ICP-MS, and the level if it had been measured by GFAAS could be in excess of $0.8 \mu \mathrm{g} / \mathrm{l}$, as values by ICP-MS may be lower by $15-16 \%$ than values by GFAAS (Table 3 ).

\section{Conclusions}

The results by the two methods for $\mathrm{Cd}-\mathrm{B}$, i.e., GFAAS and ICP-MS, correlate with each other closely enough to allow conversion when Cd-B is $\geq 2 \mu \mathrm{g} / \mathrm{l}$. Care for the method-dependent difference may be necessary when Cd-B is $2 \mu \mathrm{g} / \mathrm{l}$ or lower as the results by GFAAS would be greater than the ICP-MS results by $15-16 \%$.

\section{Acknowledgements}

The authors are grateful to the administration and staff of Kyoto Industrial Health Association, Kyoto, Japan for their interest in and support to this study.

\section{References}

1) International Programme on Chemical Safety (1992) Environmental Health Criteria. 134. Cadmium. World Health Organization, Geneva.

2) Ikeda $M$, Zhang Z-W, Shimbo S, Watanabe T, Nakatsuka H, Moon C-S, Matsuda-Inoguchi N, Higashikawa K (2000) Urban population exposure to lead and cadmium in east and south-east Asia. Sci Total Environ 249, 373-84.

3) Ikeda M, Ezaki T, Tsukahara T, Moriguchi J (2004) Dietary cadmium intake in polluted and non-polluted areas in Japan in the past and in the present. Int Arch Occup Environ Health 77, 227-34.

4) American Conference of Governmental Industrial Hygienists (2009) Cadmium and inorganic compounds. In: TLVs ${ }^{\circledR}$ and BEIs ${ }^{\circledR}$ with 7th Edition Documentation. ACGIH, Cincinnati.

5) Deutsche Forschungsgemienschaft (1999) ICP-MS collective method. Analyses of Hazardous Substances in Biological Materials Vol. 6, 79-109, Wiley-VCH, Weinheim.
6) Ikeda M, Ohashi F, Sakuragi S, Moriguchi J (2011) Cadmium, chromium, lead, manganese and nickel levels in blood of women in non-polluted areas in Japan, as determined by inductively coupled plasma-sector field mass spectrometry. Int Arch Occup Environ Health 84, 139-50.

7) Zhang Z-W, Shimbo S, Ochi N, Eguchi M, Watanabe T, Moon C-S, Ikeda M (1997) Determination of lead and cadmium in food and blood by inductively coupled plasma mass spectrometry: a comparison with graphite furnace atomic absorption spectrometry. Sci Total Environ 205, 179-87.

8) White MA (1999) A comparison of inductively coupled plasma mass spectrometry with electrothermal atomic absorption spectrometry for determination of trace elements in blood and urine from non occupationally exposed populations. J Trace Elements Med Biol 13, 93-101.

9) Ezaki T, Tsukahara T, Moriguchi J, Furuki K, Fukui Y, Ukai H, Okamoto S, Sakurai H, Honda S, Ikeda M (2003) No clear-cut evidence for cadmium-induced tubular dysfunction among over 10,000 women in the Japanese general population; a nationwide large-scale survey. Int Arch Occup Environ Health 76, 186-96.

10) Ndung'u K, Hibdon S, Flegal AR (2004) Determination of lead in vinegar by ICP-MS and GFASS; evaluation of different sample preparation procedures. Talanta $\mathbf{6 4}$, 258-63.

11) Townsend AT, O-Sullivan J, Featherstone AM, Butler ECV, Mackey DJ (2001) The application of ICP-MS and HG-AFS to the analysis of water and sediment samples from a temperate stratified estuary. J Environ Monit 3, 113-20.

12) Nuttall KL, Gordon WH, Ash KO (1995) Inductively coupled plasma mass spectrometry for trace element analysis in the clinical laboratory. Ann Clin Lab Sci 25, 264-71.

13) Zhang Z-W, Qu J-B, Watanabe T, Shimbo S, Moon C-S, Ikeda M (1999) Exposure of citizens in China and in Japan to lead and cadmium; a comparative study. Toxicol Lett 108, 167-72.

14) Coelho P, Silva S, Roma-Torres J, Costa C, Henriques A, Teixeira J, Gomes M, Mayan O (2007) Health impact of living near an abandoned mine -Case study: Jales mines. Int J Hyg Environ Health 210, 399-402.

15) Kummrow F, Silva FF, Kuno R, Souza AL, Oliveira PV (2008) Biomonitoring method for the simultaneous determination of cadmium and lead in whole blood by electrothermal atomic absorption spectrometry for assessment of environmental exposure. Talanta $\mathbf{7 5}$, 246-52.

16) Sugita M, Tsuchiya K (1995) Estimation of variation among individuals of biological half-times of cadmium calculated from accumulation data. Environ Res 68, 31-7. 